\title{
Modeling of furnace work with recirculating of heating gases for tunnel baking ovens
}

\section{Igor Litovchenko}

National University of Food Technologies, Kyiv, Ukraine

\section{Keywords:}

Ovens

Tunnel

Gas

Heating

Recirculation

Mixing

Article history:

Received 01.06.2016

Received in revised form 21.08.2016

Accepted 01.09.2016

\section{Corresponding author:}

Igor Litovchenko

E-mail:

postman3000@

yandex.ua

\section{Abstract}

Introduction. With the aim of increasing the efficiency of the sources of heat in the furnaces of tunnel ovens it was investigated the process of recycling of heating gases.

Materials and methods. In this work, we used CAEsoftware for modeling the motion of liquids, the principle of software is based on the method of finite elements. For calculation was used rheological and kinematic parameters of hot gases which were obtained for the real model experiments.

Results and discussion. It is found that the velocity distribution along the length of the furnace is divided into two sustainable region: the axis of the furnace and around the outer walls of the furnace. The mixing of the gases starts in the junction box.

The temperature of the gases at the center of the stream is reduced from 1900 to $600{ }^{\circ} \mathrm{C}$ is almost a linear relationship.

The temperature of the gases near the furnace walls varies throughout the length of the furnace ranging from $260{ }^{\circ} \mathrm{C}$ to $360^{\circ} \mathrm{C}$ because of its low turbulence flow.

On the contour of the region of maximum dissipation of kinetic energy the turbulence were observed in the two local areas. The first is the ring around the exit of products of combustion from the combustion chamber. The second area is at the area of narrowing of the furnace. It is near the exit to the junction box.

It was obtained for the first time the visual and the numerous information that reflects how the combination of local resistance in a gas path affects the value of the Reynolds criterion and the nature of the movement of the heating agent.

It is proposed to equip the furnace of this type for more details - ring washers. It is proven that they change the direction of the flow of recirculation gases so that there is an active mixing with the combustion products along the entire length of the furnace.

Conclusions. Computer modelling of furnace operation has allowed to detect and localize the flaws of the current baseline design and to propose ways of modernize of the system. 


\section{Introduction}

The bulk of the bread currently baked in tunnel baking ovens. They are universal, costeffective, the possibility of widely varying temperature settings over the length of the baking chamber.

Main unit of work which depends on the stability of the Baking Ovens - a furnace. It combusted natural gas or fuel oil.

Its principle of operation is associated with recirculation of exhaust gases heating. Flue gas with a temperature of $350 \ldots 400{ }^{\circ} \mathrm{C}$ is partially removed from the stack and partially fed into the furnace, where they are mixed with fresh products of combustion, and sent in the heating channels.

From the quality of mixing of fresh and exhaust heating gas depends on the uniformity of the heating of the baking chamber.

Definition of furnace operating parameters in the factory - a complex experimental process. Research methods are laborious and have significant errors.

It is proposed to use the methods of computer simulation. They allow to visualize the flow of hot gases inside the furnace. These methods allow you to track changes in flow rate, temperature and pressure drops, the processes of dissipation of the kinetic energy of the gas stream.

\section{Materials and methods}

In this paper FlowVision program Tesis company was used.

It is designed for the calculation of hydro - and gas dynamics problems (together with related processes warmly - and mass transfer) in a wide range of Reynolds numbers in an arbitrary three-dimensional domains.

The use of this program has allowed us to obtain unique scientific information in various sectors of the food industry [1-5]. Has been researched and proposed ways of modernization of equipment for the grinding of food $[6,7]$, for mixing food products [810], thermal processes in proofers [11-13], to transport products through pipes [14].

It was also studied the movement of heating gases in various zones of tunnel ovens [15].

The basic program is the Navier-Stokes equations, the flow continuity equation, the equation for the turbulent viscosity. In addition, the model includes equations for the turbulent energy $\mathrm{k}$ and the rate of turbulent energy dissipation $\varepsilon$.

In this paper, in the course of the simulation was used $\mathrm{k}-\varepsilon$ model of turbulent flow of viscous fluid with slight changes in the density changes at high Reynolds number.

Numerical integration of the equations of the spatial coordinates is performed using a rectangular milled locally adaptive grids. This approach allows the solution of problems carry out a grid adapted to the peculiarities of the geometry near the borders.

In the calculation were used physical parameters obtained at the time when the actual model experiments:

- the temperature of the combustion products leaving the combustion chamber is $1900{ }^{\circ} \mathrm{C}$;

- the temperature of the gases supplied to the recycling of $350{ }^{\circ} \mathrm{C}$;

- pressure drop, which is available at the site exit gas distribution box, is $30 \mathrm{~Pa}$.

The number and proportion of the feed gases was determined by the ratio of excess gas, equal to 2,15 . 
When referring to the boundary wall of the conditions of surface roughness has been set, which is characteristic of the material from which made the furnace.

In FlowVision package used several ways to visualize the results. Visualization of scalar field dissipation of kinetic energy, which is proportional to the gradient of the speed of deformation of the product, possible to determine the place of origin of turbulence in the flow. Namely education turbulence leads to a mixing of gases. Field dissipation visualized through the use of contour lines of the gradient.

Vector field visualization speed it possible to determine a change in the value of speed and change the direction of movement of the product.

Typical furnace design with mixing chamber is shown in Figure 1. It consists of a burner 1, combustion chambers 2 , the tangential entry nozzle gas recirculation 3, 4, mixing, dispensing duct chamber 5 . The latter also was simulated, as at the entrance to him to change direction of the heating gas, which affects the total gas-dynamic situation.

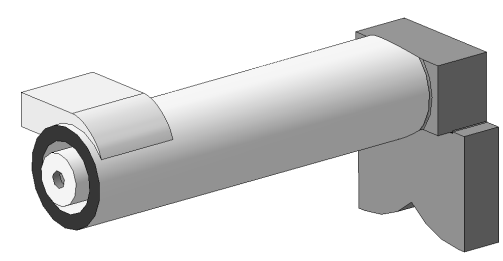

$a$

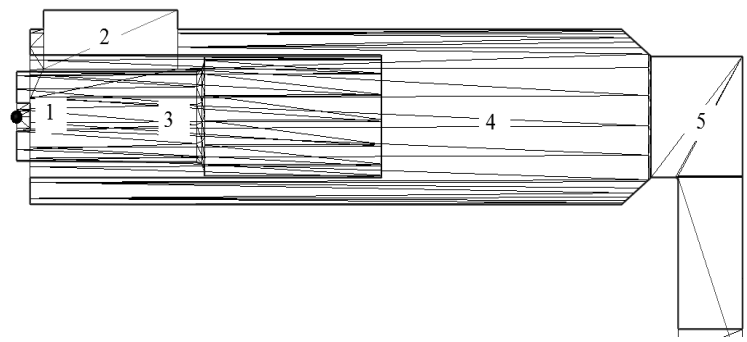

$b$

Figure 1. The appearance of the furnace tunnel baking ovens (a) and its section (b):

1 - burner; 2 - input pipe gas recirculation; 3 - combustion chamber;

4 - mixing chamber; 5 - distribution box

Examined type furnaces refers to a group of structures in which only the recycle gas is cooled outer surface of the combustion chamber and is widespread in the industry.

\section{Results and discussion} below.

The efficiency of the furnace can be estimated by graphic materials. They are presented

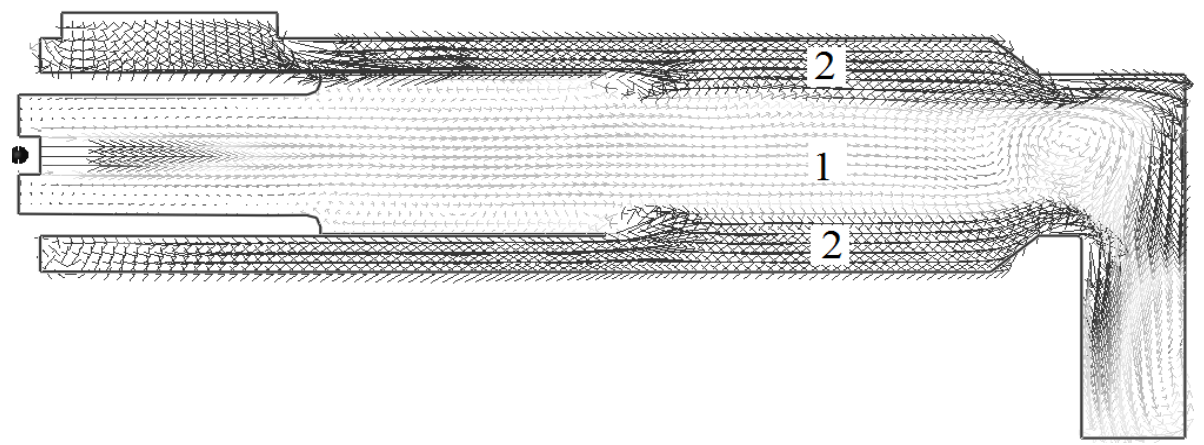

Figure 2. The velocity vector along the length of the furnace 
Analyzing the velocity distribution along the length of the furnace (Figure 2), we can distinguish two stable regions. The first region - on the axis of the furnace - gases from the combustion chamber. The second area - cylindrical - recycle gases moving around the outer walls of the furnace.

Practically there is no mixing of gases in the furnace. It begins in the switch box. It is clear that such an operation unstable and does not give a good result.

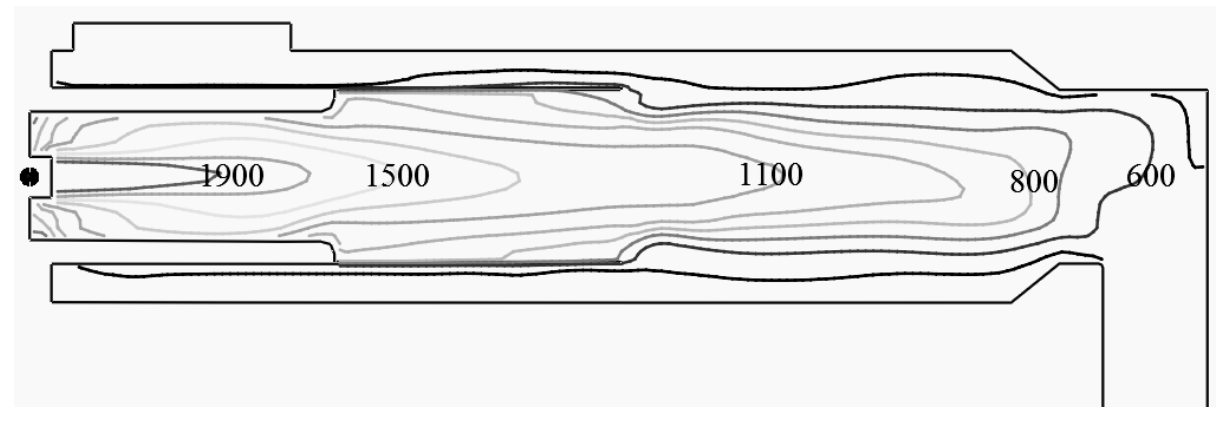

Figure 3. Isolines changes in gas temperature in the furnace

Consider the temperature drop along the length of the furnace. The flue pipes should go with the flow temperature of about $600{ }^{\circ} \mathrm{C}$. Obtaining such temperature occurs at the end of the mixing chamber (Figure 3).

Any gas pressure drop across the burner, any change in the position of valves in the distribution boxes and heating ducts lead to the inability to obtain a stable flow set temperature.

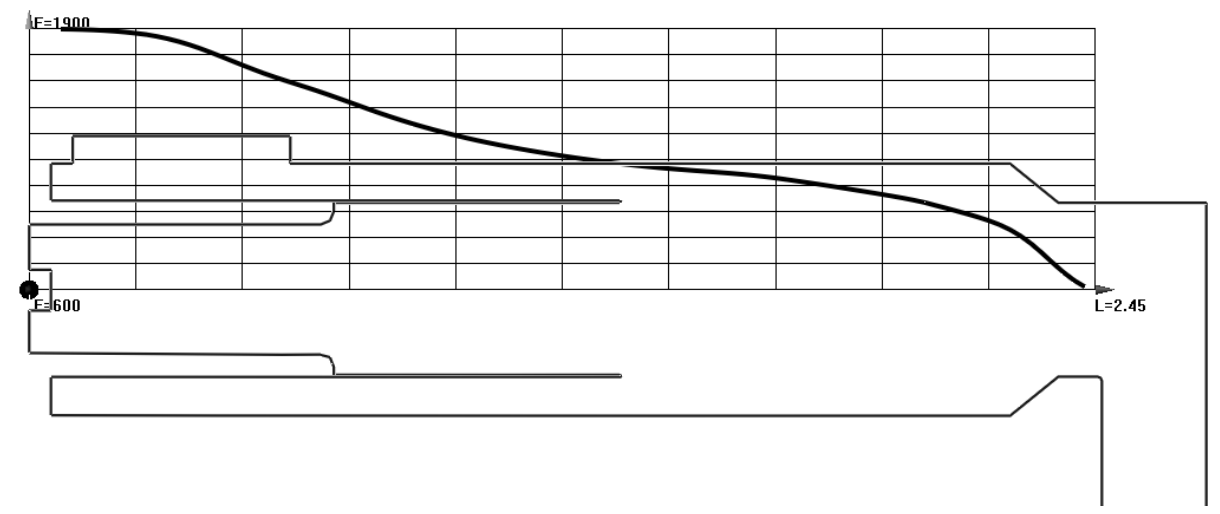

Figure 4. Schedule of changes in temperature of the combustion products in the furnace center

The temperature in the center of the flow changes from 600 to $1900^{\circ} \mathrm{C}$ virtually linear relationship (Figure 4). But efficient operation of the furnace, it should be at the beginning of the mixing zone to drop sharply. 


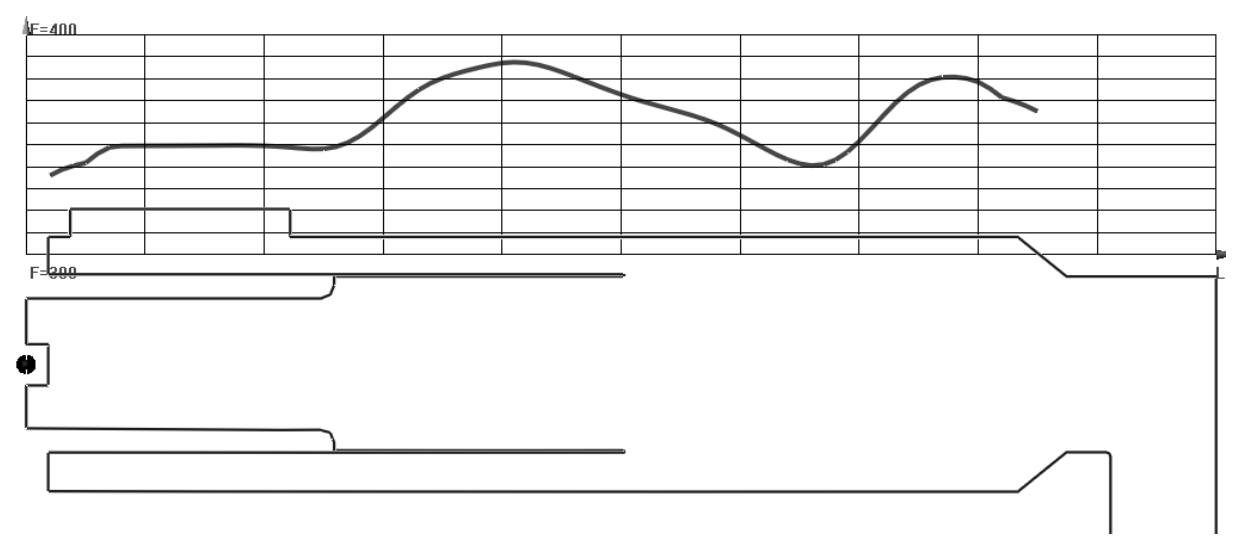

Figure 5. Schedule changes recirculation gas temperature at the outer walls of the furnace

Neither Figure 5 is a gas temperature near the furnace wall (the abscissa axis of the graph is in the middle of the annular gap through which recirculation gases move). The range of temperature fluctuations across the furnace length of about $100{ }^{\circ} \mathrm{C}$, which is clearly insufficient.

The dissipation of the kinetic energy of gases is due to internal friction between layers of flow, which are moving at different speeds. It shows the place of occurrence of turbulence, thanks to which there is a mixing of hot and cold gases.

Isolines of maximum dissipation area is shown in Figure 6. It may be noted swirls in two local areas. The first area - a ring around the exit of combustion products from the combustion chamber. The second area - in the narrowing of the furnace. It is already at the outlet to the distribution box.

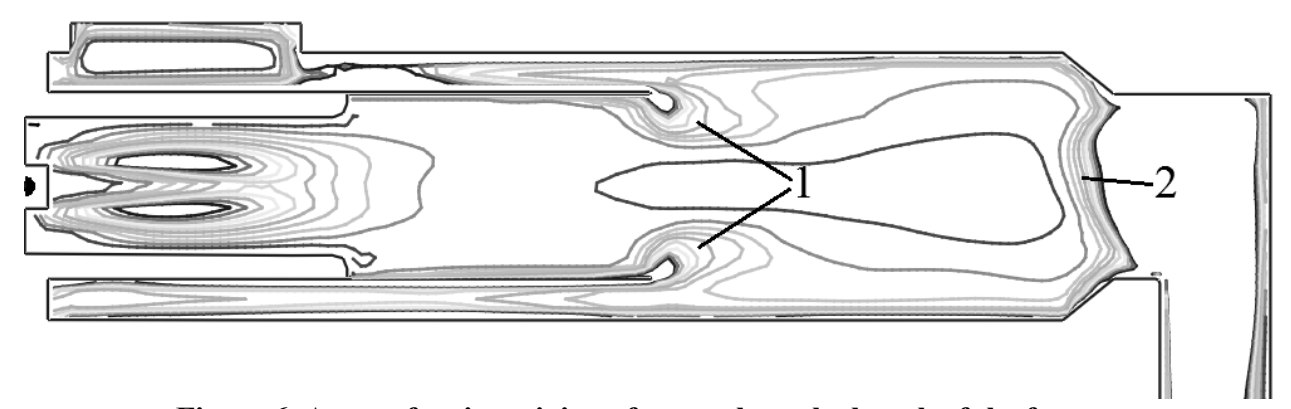

Figure 6. Areas of active mixing of gases along the length of the furnace

The above analysis allowed the furnace operation to detect and localize the shortcomings of the existing basic structure. This lack of turbulence in the gas flow.

The method of computer modeling allows us to offer solutions to the problem. Check the correctness of the proposed solutions can be directly, without the creation of pilot plants, stands and full-scale experiments.

Consider one of the solutions to the problem. 
As gas flow path is necessary to create an artificial local resistance. It will change the speed and direction of flow. This will lead to their collision and active mixing.

local resistance structure can be set. Also, there may be many places of its location. In the present embodiment, the test - A washer ring is mounted on the inner wall of the mixing chamber in the middle of its length.

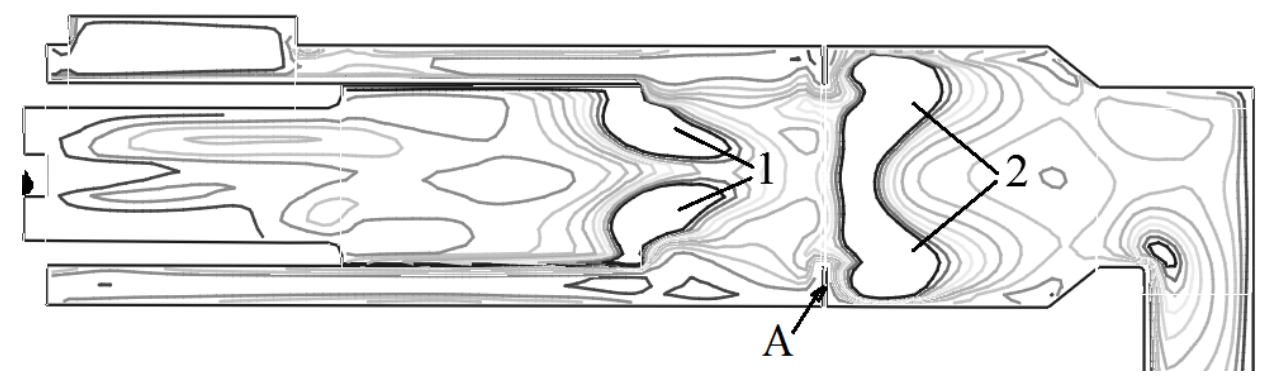

Figure 7. Changes in the activity of dissipative processes after the furnace modernization

As follows from Figure 7, activity increased mixing streams. Formed two large area at the beginning of the mixing chamber and in the middle of it. Main processes now occur in the furnace itself, rather than leaving it. This allows more precise adjustment of processes of heat exchange and mass transfer between gas flows.

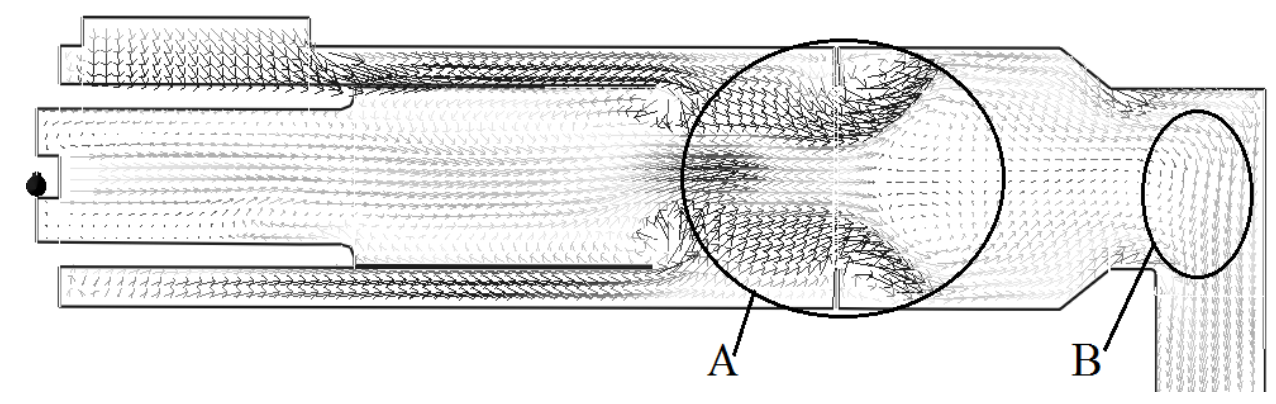

Figure 8. Velocity vector gas streams after modernization

The most visually look the field of active mixing in Figure 8. In the field of A the vector flow rates actively change direction. Streams collide and there is reduction in temperature to a predetermined value. On the contrary B - in the control box - flows have already mixed and a uniform temperature.

\section{Conclusions}

Computer modeling of complex heat exchange processes provides a unique scientific information on the furnaces ovens. 
Gas of recycling, which are introduced into the furnace tangentially to form a stable rotating flow around the chamber walls. This prevents them from mixing with fresh products of combustion.

Gas of recycling, which are introduced into the furnace tangentially, effectively cooling the outer surface of the device. Also recirculation gases effectively cooled combustion chamber surface.

The greatest area of turbulence in which the mixing gas are located at the beginning of the mixing chamber and the outlet the refrom.

It is proposed to equip the furnace of this type with additional details. They must change the direction of flow of recirculation gases so that their active mixing occurred with the combustion products over the entire length of the furnace.

Computer modeling allows you to quickly check the correctness of the proposed technical solutions for the modernization of structures of thermal devices baking ovens.

The proposed method of investigation baking ovens can be used to develop new and effective structures of this kind of baking equipment and to upgrade existing designs.

\section{References}

1. Angelov M.S., Raynov P.R. (2013), Model studies of the hydrodynamics of flow in corrugated tubes, Journal of Food and Packaging Science, Technique and Technologies, 2(3), pp. 274-282.

2. Bollada P.C. (2008), Expansion of elastic bodies with application in the bread industry, Mathematical and Computer Modelling, 48(7-8), pp. 1055-1067

3. Campbell G.M., Martin P.J. (2012), 12 - Bread aeration and dough rheology: an introduction, Breadmaking (Second edition), pp. 299-336.

4. Chiotellis E., Campbell G.M. (2003), Proving of Bread Dough II: Measurement of Gas Production and Retention, Food and Bioproducts Processing, 81(3), pp. 207-216.

5. Guy Della Valle, Hubert Chiron, Lucio Cicerelli, Kamal Kansou, Kati Katina, Amadou Ndiaye, Martin Whitworth, Kaisa Poutanen (2014), Basic knowledge models for the design of bread texture Review Article, Trends in Food Science \& Technology, 36(1), pp. $5-14$.

6. Guts V., Gubenia O., Stefanov S., Hadjiiski W. (2010), Modelling of food product cutting, 10th International conference "Research and development in mechanical industy-2010”, Donji Milanovac, Serbia, 2, pp. 1100-1105.

7. Gospodinov D., Stefanov S., Hadjiiski V. (2011), Use of the finite element method in studying the influence of different layers on mechanical characteristics of corrugated paperboard, Technical Gazette, 18(3), pp. 357-361.

8. Litovchenko I., Luchian M., Stefanov S., Csatlos C. (2012), Numerical Modeling and Simulation of Bread Dough Mixing using concept of Computational Fluid Dynamics (CFD), Proceeding of 5 International Mechanical Engineering Forum 2, June 2012, Prague, Czech Republic, p. 584-590.

9. Shpak M., Chepelyuk O., Besarab I. (2014), Simulation of fluid dispersion in ejection devices, Journal of Food and Packaging Science, Technique and Technologies, 4(1), pp. $150-154$.

10. Kudinova O., Kravchenko O., Lytovchenko I., Telychkun Y., Gubenia O., Telychkun V., Dovgun I. (2014), Modelling of process in twin-screw dough-mixing machines, Journal of Food and Packaging Science, Technique and Technologies, 5, pp. 64-68. 
11. Stanke M., Zettel V., Schütze S., Hitzmann B. (2014), Measurement and mathematical modeling of the relative of wheat dough during proofing, Journal of Food Engineering, 131, pp. 58-64

12. Jérôme Bikard, Thierry Coupez, Guy Della Valle, Bruno Vergnes (2008), Simulation of bread making process using a direct 3D numerical method at microscale: Analysis of foaming phase during proofing, Journal of Food Engineering, 85(2), pp. 259-267.

13. Peighambardoust S.H., Fallah E., Hamer R.J., A.J. van der Goot (2010), Aeration of bread dough influenced by different way of processing, Journal of Cereal Science, 51(1), pp. 89-95

14. Tetiana Vasylenko, Sergii Vasylenko, Jeanna Sidneva, Vitalii Shutiuk (2014), Best available technology - innovative methodological framework efficiency of sugar production, Ukrainian Food Journal, 3(1), pp. 122-133.

15. Litovchenko I. (2013), The study of the baking ovens by computer simulation, Food technology, XVII, pp. 107-115. 